\title{
Simulation Study on Hydraulic System Performance of Hydraulic Submersible Gate Valve Based on Ageism
}

\author{
Guijun Gao1, a , Qian Wang', b \\ ${ }^{1}$ College of Mechanical Engineering, Taiyuan University of Technology, Taiyuan 030024, China; \\ ${ }^{2}$ State-Province joint Engineering Laboratory of Mining Fluid Control, Taiyuan, 030024, China. \\ a gaogj161@163.com, b18334891@qq.com
}

Keywords: AMESim, hydraulic submersible gate valve, modeling and simulation.

\begin{abstract}
The mine drainage system is the key equipment in the early stage of mine drainage rescue. The hydraulic submersible gate valve controls the opening and closing of the drainage system, which is an important part of the mine drainage system. At present, there are few researches on hydraulic system performance of submerged sluice valve. In this paper, AMESim software was used to simulate and analyze the effect of hydraulic pressure on the hydraulic system of the submersible hydraulic submersible valve under the diving state. And analysis the pressure fluctuation of the hydraulic system is analyzed under different parameters of the pilot operated check valve. The analysis shows that with the increase of the opening pressure of the pilot operated check valve, the pressure and flow fluctuation in the piston chamber of hydraulic cylinder gradually increase. With the decrease of the flow gradient of the pilot check valve, the pressure and flow fluctuation in the piston chamber of the hydraulic cylinder gradually decrease, but the working pressure of the system will increase obviously. With the reduction of the rated flow of the pilot operated check valve, the pressure fluctuation in the piston of the hydraulic cylinder is obviously reduced, but the working pressure of the system is increased and the maximum pressure of the system is unchanged. The simulation analysis shows that the submersible gate valve will be superposed on the hydraulic system under the diving condition, which will put forward higher requirements on the sealing performance and pressure resistance characteristics of the hydraulic system, As the dive depth increases, the impact gradually increases, especially in the design and use of deep water hydraulic submersible valve should be fully considered.
\end{abstract}

\section{Introduction}

There are hundreds of coal mining companies in China, $95 \%$ of which are underground operations and the depth of coal mine working surface is usually 500 meters to 1200 meters. With the deepening of the depth and intensity of coal mining, the threat of flooding [1] faced by coal mine companies is becoming more and more serious. The excess water in down-hole operations is collected in the central pump room pool and drained out of the well with a drainage pump. When mining meets old mine water or aquifer and the water flooding into mine exceeds normal drainage capacity, it will cause flooding, which will cause serious consequences for mine construction and production and even threatens the lives of underground personnel. Article 308 of the "Coal Mine Safety Regulations" states that: For mines with complicated hydro-geological conditions, extreme complexity or danger of flooding, a waterproof gate should be installed around the underground parking yard, or based on the normal drainage system, a submersible pump that is directly controlled by the ground is installed and its drainage capacity is not less than the maximum amount of water inflow. This is often called the strong drainage system and one of the key elements that can guarantee the normal operation of the submersible pump is the submersible gate valve. According to the different driving methods, submersible gate valves can be divided into hydraulic submersible gate valves and electric submersible gate valves, this paper studies hydraulic submersible gate valve.

At present, the study on the submersible gate valve that is used to coal mines is still in its infancy, and there is less research data. Dae-Woong and Sun-Geon [2] et al studied and analyzed the load 
condition of electric actuators of electric gate valves under the liquid pressure, they studied the load effects of wedge gate valves under dynamic and static conditions respectively. The results showed that when the pressure difference between the two ends of the valve was high, the load effect of the electric actuator was high, and under the condition of high pressure difference, thrust loss accounted for about $17.6 \%$. However, the load effect was negligible at low pressure difference. Lin zhe and Ma Guangfei[3] et al studied the flow resistance characteristics and internal flow characteristics of gate valves at different inlet speeds using CFD simulations, the results of the study showed that the flow resistance and internal flow characteristics of the valve needed to be optimized before the relative opening of $2 / 8$. However, after $2 / 8$ degree of relative opening, valve flow resistance characteristics and flow characteristics were becoming stable, and it did not have the characteristics of regulating valve. Pro Quest [4] studied how the valve size, pressure, and position (opening/closing) of the gate valve affect the starting torque of gate valve. The results showed that valve size, pressure and position affected torque strongly. Augusto and Pedro Estevez Duarte et al[4] calculated the fluid flow and pressure drop of commercial gate valves using the CFD method, the value of pressure loss factor $\mathrm{k}$ in the obtained results was consistent with the previous literature description, the function of the loss factor $\mathrm{k}$ is given in the form of Reynolds number exponential equation, and through fluid CFD simulation of gate valves, they studied the micro-circulation and stagnant areas within the flow range at different opening degrees, this is crucial for the processing of food and pharmaceutical products.

This paper applies AMESim (Advanced Modeling Environment for Performing Simulations of Engineering System) [6] simulation to study the hydraulic system of hydraulic submersible gate valve. As an excellent simulation software, AMESim provides a more complete and comprehensive simulation environment for fluid, mechanical, control, electromagnetic and other engineering systems. It is based on an intuitive graphical simulation environment and used for modeling, simulation and dynamic analysis of engineering systems [7]. The main structure of hydraulic submersible gate valve and common hydraulic gate valve is the same, but their main difference is whether the hydraulic actuators are closed hydraulic systems. The hydraulic oil tanks [8] of ordinary hydraulic gate valves are open oil tank, that is, the oil tanks relate to the atmosphere to ensure the "breathing" effect of the hydraulic system, however, the oil tanks of hydraulic submersible gate valves cannot directly contact with water, therefore, the hydraulic submersible gate valve of this article uses a flexible capsule to separate hydraulic oil from water, but it can also achieve a "breathing" effect. In this paper, through the simulation analysis of the hydraulic system of the hydraulic submersible gate valve, the main factors influencing the characteristics of the hydraulic submersible gate valve are obtained, which will guide the production and use of the submersible gate valve.

\section{Hydraulic Modeling of Hydraulic Submersible Gate Valves}

The structure of hydraulic submersible gate valve mainly includes submersible motor, gate valve body, bidirectional hydraulic pump, hydraulic oil cylinder, gate valve "respirator", etc., as shown in Fig. 1. In order to ensure uniform force on the valve stem of the gate valve, a dual hydraulic oil cylinder is used to drive the valve stem of the gate valve. The basic principle is that the submersible motor drives the bidirectional hydraulic pump. The pressure oil provided by the hydraulic pump enters the hydraulic cylinder through the check valve to achieve the extension or retraction of the piston rod and the opening or closing of the gate valve. When reverse operation is required, the electric control is used to reverse the submersible motor to achieve the retraction or extension of the piston rod and then achieve the closing or opening of gate valve. In this hydraulic system, the choice of pilot-operated check valve is very important, the opening pressure [9] and flow characteristics, etc., of pilot-operated check valve directly affect the stability of the hydraulic system [10]. During process of expansion and contraction of the piston rod, the hydraulic oil of the hydraulic cylinder needs to flow and exchange with the hydraulic oil of the tank. This will create the "breathing" effect of the hydraulic system. For general hydraulic systems, hydraulic oil tank connects with atmosphere to achieve the exchange with the atmosphere. But for submersible gate valve, hydraulic oil tank cannot 
connect with atmosphere directly, we use rubber soft capsules to separate hydraulic oil from water, meanwhile it can achieve the respiration of the hydraulic system and use water to compensate for changes in hydraulic oil volume[11], however, when the hydraulic system put into water, it is equivalent to adding a pressure to the hydraulic oil tank of the hydraulic system, the pressure acting on the hydraulic tank is different at different depths of diving. In order to study the above characteristics, a simulation model is established, as shown in Fig. 2. The physical parameters of various components are shown in Table 1.

Table 1. Physical parameters of each component

\begin{tabular}{ccc}
\hline No & Structure name & Parameter description \\
\hline 1 & Motor & Rated speed 1380r/min \\
2 & Bidirectional hydraulic pump & Displacement $1 \mathrm{ml} / \mathrm{r}$, The highest pressure 120bar \\
3 & Double hydraulic cylinder & Rod diameter $40 \mathrm{~mm}$, Cylinder bore $80 \mathrm{~mm}$, stroke 250mm \\
4 & Simulated load of hydraulic cylinder & Single hydraulic cylinder 1000kg \\
\hline
\end{tabular}

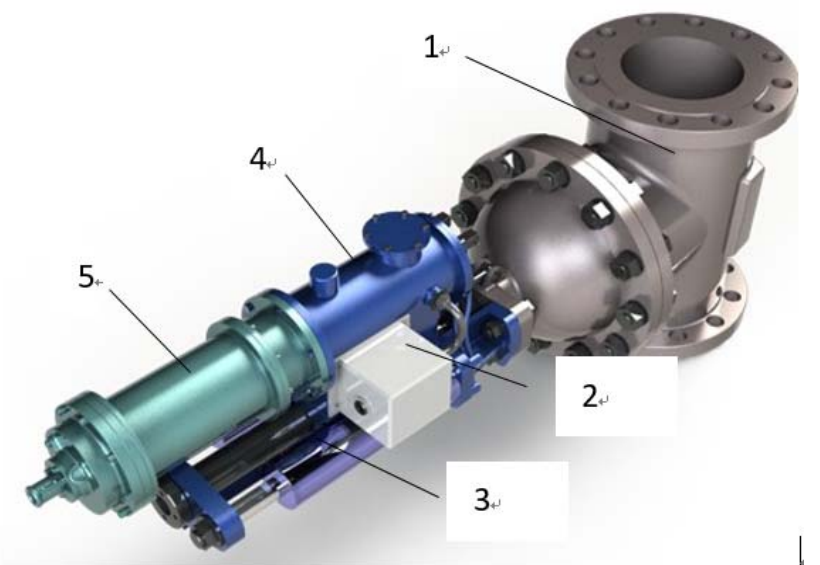

1-gate valve body; 2-gate valve "respirator"; 3-hydraulic cylinder; 4-bidirectional hydraulic pump; 5-submersible motor

Fig 1. Structure principle of submersible hydraulic gate valve

Hydraulic principle model of hydraulic submersible gate valve is established in AMESim (Fig. 2), this model includes sub-models that belong to hydraulic, mechanical, signal model libraries, which are in AMEsim, and reasonable sub-models should be selected based on specific physical structure, working principles, and the phenomenon of concern during the study. Sub-models' functions are shown in Table 2.

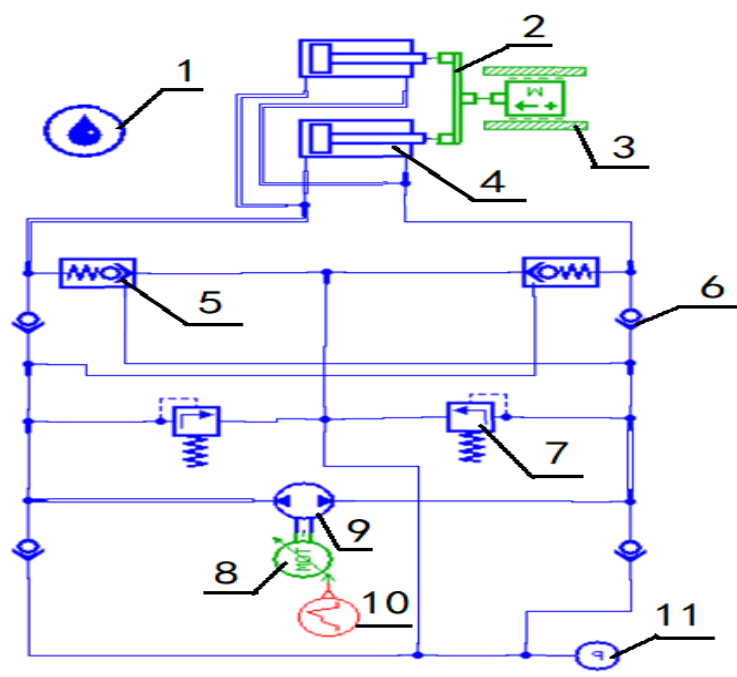

Fig 2. Simulation model of hydraulic system of submersible gate valve 
Table 2. Main function of sub-model

\begin{tabular}{|c|c|c|c|}
\hline $\begin{array}{l}\text { The No of } \\
\text { Fig. } 2\end{array}$ & Sub-model functions & $\begin{array}{l}\text { Affiliated model } \\
\text { library }\end{array}$ & Setting parameters \\
\hline 1 & $\begin{array}{l}\text { Liquid performance } \\
\text { parameter }\end{array}$ & Hydraulic library & Liquid type \\
\hline 2 & Linear Link Node & Mechanical library & Connect two cylinders \\
\hline 3 & Mass load & Mechanical library & Setting the load \\
\hline 4 & Hydraulic cylinder & Hydraulic library & Setting parameters of cylinder \\
\hline 5 & $\begin{array}{l}\text { Pilot-operated check } \\
\text { valve }\end{array}$ & Hydraulic library & $\begin{array}{c}\text { Setting parameters of pilot-operated check } \\
\text { valve }\end{array}$ \\
\hline 6 & Check valve & Hydraulic library & Parameters of check valve \\
\hline 7 & Relief valve & Hydraulic library & Parameters of relief valve \\
\hline 8 & Hydraulic pump & Hydraulic library & Parameters of displacement and speed \\
\hline 9 & Motor & Motor Library & $\begin{array}{l}\text { Transforming electrical signals into } \\
\text { mechanical energy }\end{array}$ \\
\hline 10 & $\begin{array}{l}\text { Piecewise linear signal } \\
\text { source }\end{array}$ & Signal library & Setting rotation of the motor \\
\hline 11 & Constant pressure source & Hydraulic library & $\begin{array}{l}\text { Simulating the external environmental } \\
\text { parameters of diving }\end{array}$ \\
\hline
\end{tabular}

According to the parameters in Table 1, the parameters of the original in Figure 1 are set in the simulation model and each element uses a basic mathematical model. Piecewise linear signal source is set to three stages, the first stage is the motor start stage, and the $2 \mathrm{~s}$ speed is set from 0 to $1380 \mathrm{r} / \mathrm{min}$; The second stage is the forward rotation stage, during which hydraulic oil enters the piston chamber of the hydraulic cylinder, the time is set to $118 \mathrm{~s}$, constant speed is $1380 \mathrm{r} / \mathrm{menthe}$ third stage is the reverse rotation stage, at which stage the hydraulic oil is pushed into the piston chamber, the time is set to $110 \mathrm{~s}$, constant speed is $-1380 \mathrm{r} / \mathrm{min}$. Hydraulic submersible gate valve is mainly used in mine strong drainage system, the maximum diving depth of the hydraulic submersible gate valves does not exceed 100 meters during the strong drainage process, therefore the constant pressure source pressure is set to 10bar, which is used to simulate the external water pressure through the soft capsule "Respirator" to transfer the water pressure to the hydraulic oil tank when the hydraulic submersible valve maintains "dive" state, the time of operating parameter is set to 230 s and the display interval time is set to $1 \mathrm{~s}$.

\section{Analysis of Simulation Results}

\subsection{The Influence of Opening Pressure of Pilot-Operated Check Valve on the System.}

The opening pressure of pilot-operated check valve is set to 5 bar, 10 bar, and 15 bars respectively for simulation, the simulation results are shown in Fig. 3 and Fig. 4. Fig. 3 shows the fluctuation of the pressure in the piston chamber of the hydraulic cylinder when the pilot-operated check valve is set with different opening pressures. With the increases of the opening pressure of the pilot-operated check valve, the pressure fluctuation range of the piston chamber of the hydraulic cylinder becomes larger and larger, and there are also some slight fluctuations between 150s-200s. Fig. 4 shows the flow fluctuations in piston chamber of hydraulic cylinder when the opening pressure of pilot-operated check valve is set to different opening pressures, with the increases of the opening pressure of the pilot-operated check valve, the pressure fluctuation range of the piston chamber of the hydraulic cylinder becomes larger and larger, and there are also some slight fluctuations between 150s-200s. As can be seen from Fig. 3, the maximum pressure of the system is $130 \mathrm{bar}$, but the pressure of relief valve is set to 120 bar, it shows that the pressure (10 bar) of the constant pressure source is superimposed on the system. Therefore, when hydraulic operated submersible gate valve dives underwater, the external water pressure will be superimposed on the pressure of the hydraulic system, it will affect the sealing performance of the seals, joints and other components of the hydraulic system, especially for those hydraulic gate valves with deep diving depth. Therefore, water pressure needs to be taken into account in the design and manufacture of hydraulic systems. 


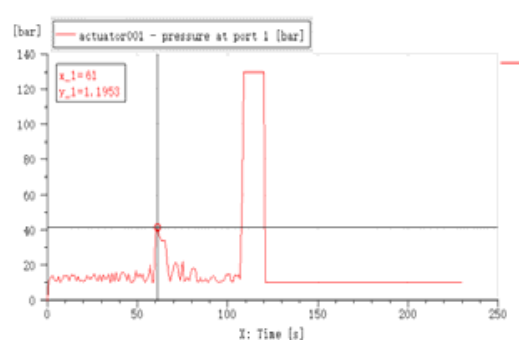

(e) 5 bar

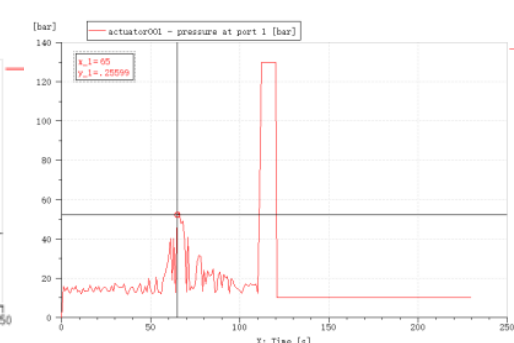

(f) $10 \mathrm{bar}$

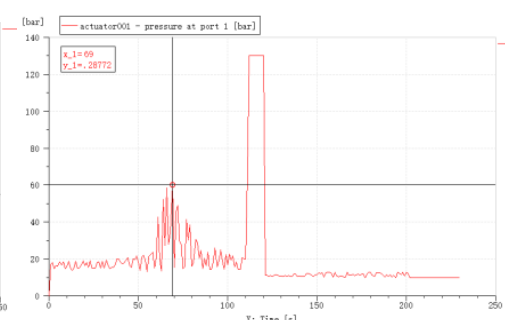

(g) $15 \mathrm{bar}$

Fig 3. The change of pressure in piston chamber of hydraulic cylinder with the opening pressure of pilot-operated check valve

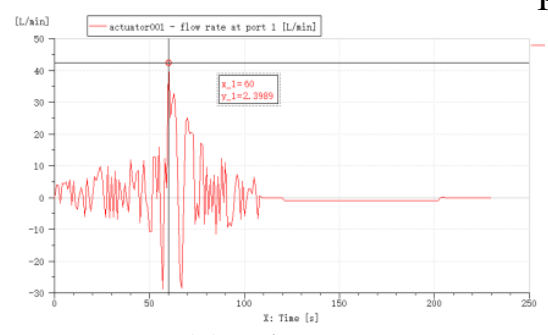

(a) 5 bar

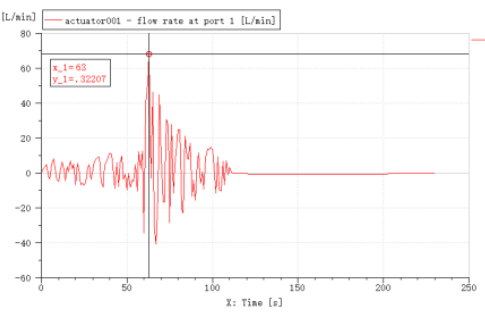

(b) 10 bar

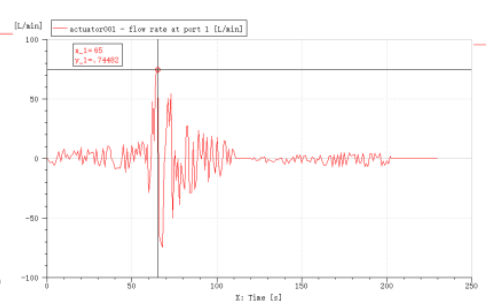

(c) 15 bar

Fig 4 . The change of flow in piston chamber of the hydraulic cylinder flow with the opening pressure of pilot-operated check valve

\subsection{Influence of Flow Gradient of Pilot-Operated Check Valve on System.}

The flow gradient of pilot-operated check valve is set to $5 \mathrm{~L} / \mathrm{min} / \mathrm{bar}, 1 \mathrm{~L} / \mathrm{min} / \mathrm{bar}$, and 0.1 $\mathrm{L} / \mathrm{min} /$ bar respectively for simulation, the results of simulation are shown in Fig. 5, Fig. 6. Fig 5 shows the pressure fluctuations in the piston chamber of the hydraulic cylinder when the pilot-operated check valve is set with different flow gradients, with the decrease of the flow gradient of the pilot-operated check valve, the pressure fluctuation range in piston chamber of the hydraulic cylinder is getting smaller and smaller. When the pressure gradients are $5 \mathrm{~L} / \mathrm{min} / \mathrm{bar}$ and $1 \mathrm{~L} / \mathrm{min} / \mathrm{bar}$, violent oscillation occurs between $60 \mathrm{~s}$ and 80 s on the abscissa, maximum pressure shock are between 70 bar and 80 bars. When the pressure gradient is set to $0.1 \mathrm{~L} / \mathrm{min} / \mathrm{bar}$, there is no fluctuation in piston chamber pressure of hydraulic cylinder, however, the working pressure of the system has increased significantly, approaching 60 bars. Fig. 6 shows the flow fluctuation in the piston chamber of the hydraulic cylinder when the pilot-operated check valve is set with different flow gradients, its law of change and the law of pressure change are basically similar, when the pressure gradient is set to $0.1 \mathrm{~L} / \mathrm{min} / \mathrm{bar}$, the flow tends to be stable.

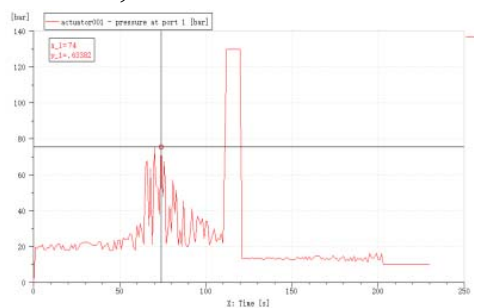

(a) $5 \mathrm{~L} / \mathrm{min} /$ bar

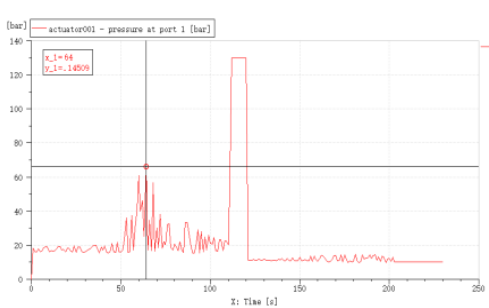

(b) $1 / \mathrm{L} / \mathrm{min} / \mathrm{bar}$

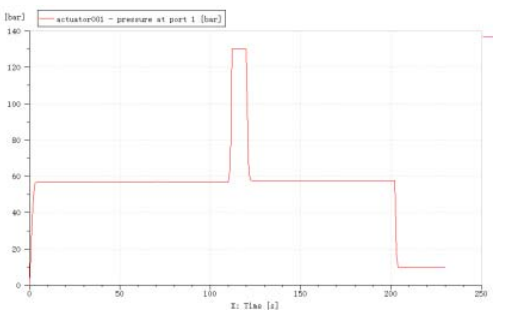

(c) $0.1 \mathrm{~L} / \mathrm{min} / \mathrm{bar}$

Fig 5. The change of the pressure in the piston chamber of hydraulic cylinder with the flow gradient of the pilot-operated check valve

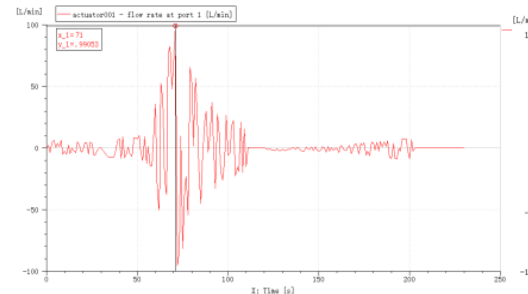

(a) $5 \mathrm{~L} / \mathrm{min} / \mathrm{bar}$

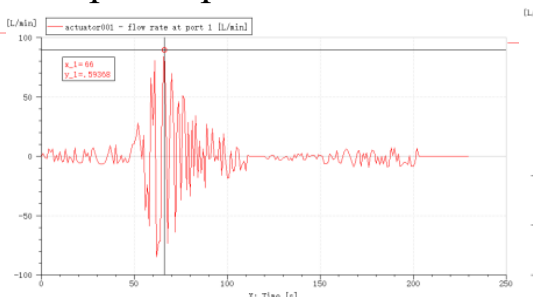

(b) $1 \mathrm{~L} / \mathrm{min} / \mathrm{bar}$

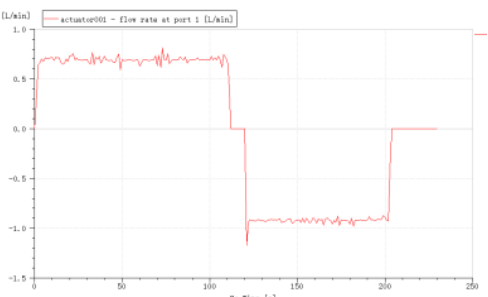

(c) $0.1 \mathrm{~L} / \mathrm{min} / \mathrm{bar}$

Fig 6. The fluctuations of flow in piston chamber of hydraulic cylinder with the flow gradient of pilot-operated check valve 


\subsection{Influence of the Rated Flow of Pilot-Operated Check Valve on the System.}

The rated flow of the pilot-operated check valve is set to $5 \mathrm{~L} / \mathrm{min}, 1.5 \mathrm{~L} / \mathrm{min}$, and $1 \mathrm{~L} / \mathrm{min}$ respectively for simulation, the results of simulation are shown in Fig. 7 and Fig. 8. Fig. 7 shows the pressure fluctuations in the piston chamber of the hydraulic cylinder when the pilot-operated check valve is set to different rated flow. With the decrease of the rated flow of the pilot-operated check valve, the pressure fluctuations in the piston chamber of the hydraulic cylinder reduce significantly. However, with the decrease of the rated flow of the pilot-operated check valve, the working pressure of the system has increased and the maximum pressure of the system has not changed. Fig. 8 shows the flow fluctuation in the piston chamber of the hydraulic cylinder when the pilot-operated check valve is set to different rated flow. With the decrease of the rated flow of the pilot-operated check valve, the flow fluctuations in piston chamber of the hydraulic cylinder reduce significantly, in the case of $1 \mathrm{~L} / \mathrm{min}$, the maximum instantaneous flow rate of the system reaches about $17 \mathrm{~L} / \mathrm{min}$, it is obviously less than the instantaneous maximum flow of $75 \mathrm{~L} / \mathrm{min}$ at $5 \mathrm{~L} / \mathrm{min}$.

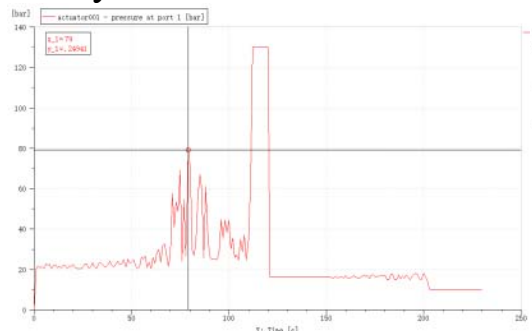

(a) $5 \mathrm{~L} / \mathrm{min}$

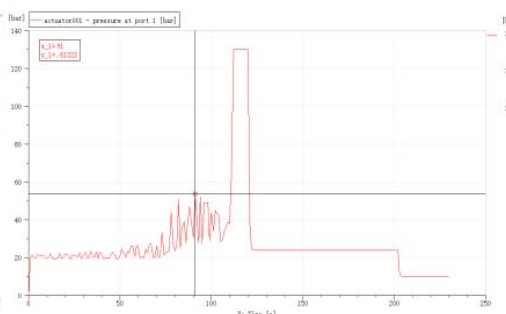

(b) $1.5 \mathrm{~L} / \mathrm{min}$

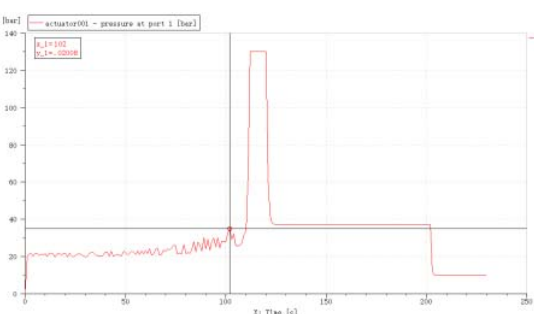

(c) $1 \mathrm{~L} / \mathrm{min}$

Fig 7. The change of pressure in piston chamber of hydraulic cylinder with the rated fow of the pilot-operated check valve

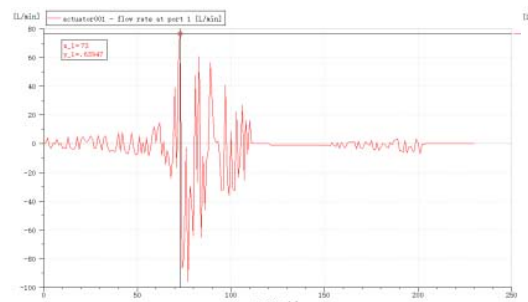

(a) $5 \mathrm{~L} / \mathrm{min}$

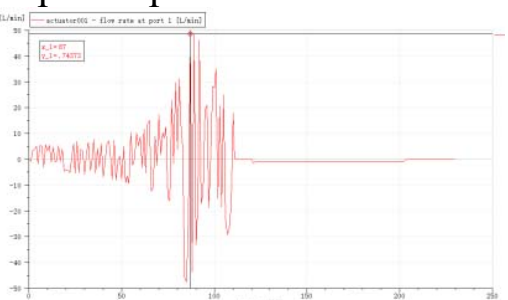

(b) $1.5 \mathrm{~L} / \mathrm{min}$

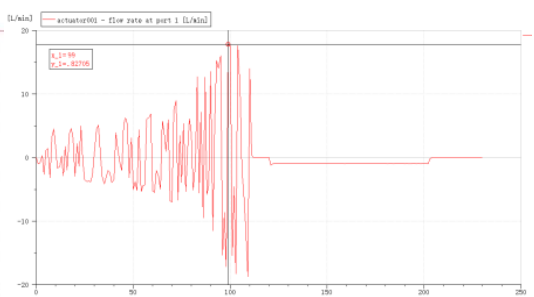

(c) $1 \mathrm{~L} / \mathrm{min}$

Fig 8. The change of flow in piston chamber of hydraulic cylinder with the nominal flow of pilot-operated check valve

\subsection{Optimized Parameter Simulation.}

According to the above results of analysis, it is necessary to reduce the fluctuations of pressure and flow, but also to prevent system pressure from rising, therefore, the opening pressure of the pilot-operated check valve is set to $5 \mathrm{bar}$, the flow gradient is set to $0.2 \mathrm{~L} / \mathrm{min} / \mathrm{bar}$, and the rated flow is set to $1.2 \mathrm{~L} / \mathrm{min}$, then the simulation is performed again. The results are shown in Fig. 9 and Fig. 10. Fig. 9 shows the change of pressure in piston chamber of hydraulic cylinder, it can be seen that the system pressure does not fluctuate at each stage, the working pressure of the system is about 20bar, the maximum pressure of the system is $130 \mathrm{bar}$, and the base pressure of system is 10bar. Fig 10 shows the change of flow in the piston chamber of the hydraulic cylinder, it can be seen that the flow of the system is very stable and there is no fluctuation. Therefore, several parameters (opening pressure 5 bar, flow gradient $0.2 \mathrm{~L} / \mathrm{min} / \mathrm{bar}$, rated flow $1.2 \mathrm{~L} / \mathrm{min}$ ) of pilot-operated check valve provide certain reference for the design and use of hydraulic submersible gate valve.

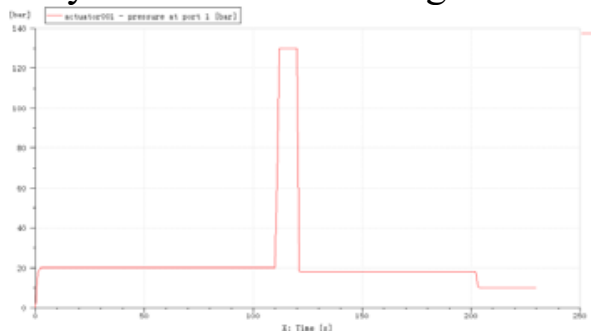

Fig 9. The change of pressure in piston chamber of Hydraulic cylinder 


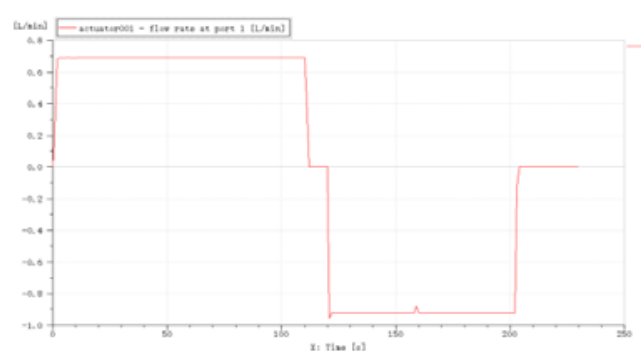

Fig 10. The change of flow in piston chamber of Hydraulic cylinder

\section{Summary}

This paper uses AMESim software to simulate the hydraulic system of hydraulic submersible gate valve, the "diving" status of the submersible gate valve is simulated by setting the pressure of the constant pressure source, the results of the study indicate that the submersible gate valve's water pressure under diving status is superimposed on the hydraulic system, it imposes higher requirements on the sealing performance and pressure resistance characteristics of hydraulic system, the deeper the depth of the dive, the greater the impact, especially for the use of hydraulic submersible gate valve in deep water, it should be fully considered in the design and use of hydraulic submersible gate valve. In addition, by changing the different parameters of the pilot-operated check valve, the fluctuation of pressure and flow of hydraulic system is simulated and analyzed under different parameters of pilot-operated check valve, the results of the study show that as the opening pressure of the pilot-operated check valve increases, the fluctuations of pressure and flow in piston chamber of the hydraulic cylinder are getting bigger and bigger; as the flow gradient of the pilot-operated check valve decreases, the fluctuations of pressure and flow in piston chamber of the hydraulic cylinder are getting smaller and smaller, however, the working pressure of the system increases significantly; and as the rated flow of the pilot-operated check valve decreases, the pressure fluctuation in the piston chamber of the hydraulic cylinder reduces significantly, however, the working pressure of the system increases and the maximum pressure of the system does not change. The research results have guiding significance for the further study of the performance of submersible valve actuators and the increase of the depth of submersion. The results of study are instructive for the further study of the performance of submersible valve actuator and the increase of diving depth.

\section{References}

[1]. Qiang Wu, Fanpeng Cui, Qisu Zhao, et al. Type classification and main characteristics of mine water disasters[J]. Journal of China Coal Society, 2013, 38(4).

[2]. Dae-Woong Kim, Sun-Geun Park, Sin-Cheul Kang, Yang-Suk Kim A study on the phenomenon of rate of loading in motor operated gate valves. Nuclear Engineering and Design. 240 (2010) 957-962.

[3]. Zhe Lin, Guangfei Ma, Baoling Cui, Yi Li, Zuchao Zhu, Nansen Tong. Influence of flashboard location on flow resistance properties and internal features of gate valve under the variable condition. Journal of Natural Gas Science and Engineering. 33 (2016) 108-117.

[4]. ProQuest. The effects of valve wheel size, operation position and in-line pressures on required actuation torque for gate valves. Dissertations Publishing 1997.

[5]. Augusto, Marcelo, De Gruyter. Using Computational Fluid Dynamics (CFD) for Evaluation of Fluid Flow Through a Gate Valve. International Journal of Food Engineering. 2012, Vol.8(4).

[6]. Hongbin Yuan, Minqing Zhang, Yantang Sun. AMEsim-based simulation analysis of dynamic characteristics of direct-acting solenoid valve[J]. Journal of Rocket Propulsion. 2011, 37(5). $30-35$. 
[7]. Yongling Fu, Xiaoye Qi. Modeling and Simulation of AMESim system[M].Beijing University of Aeronautics and Astronautics Press,2006.

[8]. Cengtong Sun, Guohua Chen, Xuehua Jiang, et al. Research of hydraulic system simulation technology and software[J]. MECHINE TOOL \& HYDRAULICS. 2008, 36(10) 140-143.

[9]. Peiqun Su, Zhihui Deng, Xiliang Zhang. Study on control characteristics on hydraulic control one-way valve in locking circuit[J]. MECHINE TOOL \& HYDRAULIC. 2014, 42(13) 15-18.

[10]. Cunzhi Yang. Research on motion stability of hydraulic cylinder[J]. Coal Mine Machinery. 2005. 11. 62-64.

[11]. Lixun Zhang, Zhuo Wang, Liquan Wang, et al. Automatic compensating deep water hydraulic power station and underwater working tools[J]. MACHINE TOOL \& HYDRAULICS. 1998.2.39-40. 